\title{
Challenges and Advantages of Community Participation as an Approach for Sustainable Urban Development in Egypt
}

\author{
Ayman M. Nour \\ Associate Prof. of Architecture, Helwan University, Egypt \\ E-mail: a_afify@helwan.edu.eg
}

\begin{abstract}
The structural heterogeneity of formal and informal residential and economic spheres in Egypt, as in many countries of the South, continues to increase disparities and aggravate the social and environmental problems of the urban poor. In recent years, a shift has taken place to incorporate local communities as active partners into urban upgrading and development interventions. The following paper will discuss the experience of the Participatory Urban Development Project in Egypt. It tries to identify and demonstrate mechanisms and solutions for the manifold and interrelated problems which could then be applied in other informal areas, too. In doing so, the paper focuses particularly on promoting community participation and multi-actor partnerships without which any attempt to achieve remarkable and sustainable impacts is bound to fail. The paper will give an overview of informal residential development, the institutional framework and the dominant physical and socio-economic features followed by a brief presentation of the strategies, areas of action, potentials and obstacles faced by the project.
\end{abstract}

Keywords: Challenges, Community participation, Urban development, Sustainability, Egypt

\section{Introduction}

In most cities in developing countries, the dramatic pace of demographic, economic, and social change severely overburdens the capacity of local authorities to provide urgently needed housing and urban services. In fact, the challenge of providing adequate service cannot be met through investment in technical facilities alone; the required funding is just not available and the needs and problems themselves are evolving too rapidly. In these circumstances, service provision depends very much on an efficient organization of service delivery processes and the best possible use of available material and human resources. It is mainly a question of management, which calls for active cooperation between government agencies and housing and urban services users, as well as private sector actors. (Schubeler, Peter, 1996)

Participation should be justified on the basis of its contribution toward the objectives of housing and urban management. While participation may also serve broader social and political goals, the decision to employ a participatory approach must in the first place be based on the contribution of this approach toward the goals of housing and urban systems and the effectiveness and efficiency of service delivery. Participatory housing and urban management requires that user communities and responsible institutions have both the capacity and the opportunity for participation. While this may seem self-evident it raises the crucial point that participatory processes have specific requirements in terms of resources, time, and skills; the necessary capacity must be established and adequate opportunities for participation created. And participation is always associated with empowerment of the participants. (Smith, M. K. 2006)

\section{Literature Review}

The study of the potential of challenges and advantages of community participation for sustainable urban development compels us to make explicit our assumptions about four main topics, which will include first the concept of participation, then definition of participation, and the scope of participatory strategies where the last topic will review the main constraints for participatory strategies the definitions of sustainability and Sustainable development.

\subsection{Concept of participation}

The concept of participation in development activities is certainly not a new one. According to Caroline, in rural development, community participation has been recognized as an essential component at least since the early 1950s. The importance of participation in urban development activities has lagged behind. One reason may be that rural projects are mainly production oriented, and it is quite evident that the beneficiaries-as producers-must be involved in the development of production systems. In urban projects, beneficiaries have been seen primarily as consumers of services, and their role in developing supply systems has therefore been accorded less importance. Experience with participatory housing and urban development projects demonstrate that community-based organizations and housing users can make important contributions to the provision and operation and maintenance of housing and urban systems. Benefits derive not only from cost reduction and resource mobilization, but also from better targeting of project measures to peoples' real needs through their involvement in the planning phase. User participation is an integral aspect of demand-oriented housing and urban development. Furthermore, participation enhances the "ownership" of the facilities by the user community 
and thus ensures more extensive and efficient use of facilities, better maintenance, and more reliable operation (Moser, Caroline O.N.1987).

\subsection{Definition of participation:}

Participation in housing and urban service management is a process whereby people -as consumers and producers of housing and urban services and as citizens-influence the flow and quality of housing and urban services available to them. Participation is based on voluntary relationships between various actors, which may include government institutions, individual housing and urban services users, community-based organizations, user groups, private enterprises, and non-governmental organizations. On other words we can define participation in housing and urban service management with regard to the context of participation, the concerned actors, orientation toward processes, and the nature of relationships that it involves, its implications may be described briefly:

\subsubsection{Context:}

Participation is not limited to development projects but includes many activities that take place in normal day-to-day city life outside of the project context. These range from the micro-scale, including such activities as community-based maintenance of local drains, to the macro-scale, including public support for government-sponsored environmental protection programs. Although isolated self-help activities as such are not regarded as "participation," participatory strategies build on existing processes of informal and self-help housing and urban development-supporting them where possible and rendering them more effective by linking them to formal housing and urban Systems.

\subsubsection{Process:}

Participation refers to a process and not a product. What counts, in other words, is not simply the share of benefits that participants receive but the role they play in determining the evolution of delivery of housing and urban services.

\subsubsection{Actors:}

The participants concerned are not limited to residential communities; they may be any grouping of housing users or even individual users and also include private sector enterprises in particular.

\subsubsection{Relations:}

Participatory housing and urban service management depends on voluntary relationships between two or more groups, actors, or stakeholders. This implies that participation is a two-way process; it is concerned not just with the inputs of beneficiaries to a project or program but with the interaction on a continuing basis between beneficiaries, government, and others. Participatory relationships are voluntary and their effectiveness will depend on each stakeholder being convinced that the process serves his or her interests.

\subsection{Scope of Participatory Strategies}

In the next section we will present and analysis the different strategies of participation in urban development projects which include a variety of processes of relationships between user communities, government institutions, and private sector actors. In this section, a simple typology of four participatory approaches is proposed as a general framework for considering and comparing options for participatory housing and urban service management. Participation exists in a wide variety of forms, ranging from government involvement in community-based development activities to people's participation in government-directed management functions these approaches are in no way exclusive and often take place at the same time (ADB. 2006). (figure 1)

\subsubsection{Community-based strategy}

The main objectives of community-based strategy are to support the local urban development; enhance capacity of local community groups to manage urban service development; and enable these processes through appropriate changes in the legal, technical, and policy context. Typical actions include organizational and technical extension services. Enabling actions involve recognition of people's rights to self-help housing and urban improvements, tenure security, and awareness building programs. According to Schubeler, the principal strengths of this approach derive from creative learning and the community's potential for self-organization. However, this strategy does not always succeed in introducing representative and functionally oriented organizations. The bottom-up, community-based approach also faces inherent difficulties in linking locally developed housing and urban systems to municipal networks. The approach is seldom able to mobilize more than a modest volume of resources (Schubeler, Peter. ibid. 1996.).

\subsubsection{Area-based strategy}

The second form of participatory strategies is area-based strategy; this form of participatory strategies deal with the social group, in a particular residential area constitutes the frame of reference of development efforts. Programs involve beneficiaries at various stages of the development process, with the principle objective of improving the efficiency and cost effectiveness of government activities. Typical actions include awareness building, community participation in demand analysis and the choice of solutions, and mobilization of resources 
for implementation and operation and maintenance. Organizational capacity-building may also be introduced. This approach is well suited for channeling larger volumes of resources and for ensuring more effective linkages between local level development and municipal Systems. Improvement measures may become standardized and supply-driven; however, loss of community "ownership" and poor cost recovery are common problems with this approach.

\subsubsection{Functionally based strategy}

The main objectives of functionally based strategy approach are first to designate areas of responsibility within which each stakeholder may pursue particular interests and exercise capacities, and second to establish effective collaboration between these various domains. Typically, a community group will take responsibility for managing and financing "internal" activities such as local garbage collection, while the municipality will ensure the "external" tasks such as onward transfer and disposal of waste materials. According to Schubeler, subsidiary programs of community development and organizational and technical support are also important along with training and awareness building. The strength of functionally based collaborative approaches lies in the relatively high level of empowerment of participating community groups. Because project implementation and financing remain more clearly in community hands, loss of project ownership" and poor cost recovery do not become problems. The most important difficulties concern coordination and linkage between the internal facilities and the government-sponsored "external" facilities.

\subsubsection{Process-based strategy}

The last strategy is the process-based strategy, the basic objective is to improve the efficiency, demand responsiveness, and accountability of housing and urban service management through a general decentralization of delivery processes. Decentralization implies a double movement of on the one hand, devolving decision-making processes and operational responsibility to more local bodies and, on the other hand, opening management functions at each level to the exchange of information from below. Privatization of specific service delivery tasks and other forms of public-private partnerships are important decentralization strategy measures. Decentralization strategies depend upon measures of institutional development to increase responsibility and authority to local bodies and develop their capacity. The strength of a decentralization strategy derives from both its mobilization of creative capacities at all levels of society, and its more productive use of available capacities and potentials.

\subsection{Constraints for participatory strategies}

According to Schubeler, Different constraints for participatory strategies impede the success of the possibility of effective participation between the different elements of urban development programs in developing countries; these constraints include factors deal with the legal constraints, regulations and technical standards, planning methods, project management procedures, or absence of a workable model. Next we will analysis briefly the different constraints for participatory strategies as in figure 2 (Schubeler, Peter. ibid. 1996). (figure 2)

\subsubsection{Legal constraints}

The first constraint for participatory strategies is the legality. According to Schubeler, the fact that high proportions of the residents of informal residential areas (which often constitute up to one-half of a developing city's housing units) do not possess legal title to their plot constitutes an important constraint to their participation. As service provision amounts to defect recognition of property rights, it is a step which the technical" agencies responsible for housing and urban service provision are neither willing nor authorized to take. To resolve this problem, governments may create special programs for "regularizing" informal settlements, meaning the legalization of land tenure, layout corrections, and service upgrading.

\subsubsection{Regulations and technical standards.}

Further constraints to participation derive from the regulations and technical standards which municipal governments apply to housing construction. Full compliance with prevailing housing and urban service regulations and standards often raises the price of housing and urban services beyond the means of low-income households. While a certain level of subsidy is sometimes required, real participation is only possible when the applied solutions are more or less affordable.

\subsubsection{Planning methods}

Current planning methods and procedures often delay participation in housing and urban development. The conservative master plan embodies a conceptual approach, which is in many ways antithetical to participatory, community-based, bottom-up planning. Conservative planning is a top-down process that focuses on the desired future state of a single housing and urban sector, which is viewed as a spatially extended technical network. Implementation is normally organized into distinct stages projects) that aim to achieve the design capacity by a target date. As housing and urban service users, people figure as parameters, external to the system, but essential to defining its performance requirements for example in calculating liters per capita per day. 


\subsubsection{Project management procedures}

in addition to planning methods, the administrative procedures and practical interests of external support agencies often restrict the scope of participatory housing and urban development. To control timing of activities and expenditures under a development project, project planners and managers must formulate an implementation schedule and budget in advance. To ensure that these are respected, there is a tendency to limit the beneficiaries' role in the planning phase to one-way consultation as opposed to genuine participation in decision-making

\subsubsection{Absence of a workable model}

The last constraint for participatory strategies is the absence of workable model. The participatory approach usually implies important innovations for the responsible government institution. Bureaucratic resistance to change and the mere fact that it has never been done before, constitute major hindrances to the introduction of participatory approaches. Even when the will to introduce participation is present, lack of knowledge of required inputs of time, skills and resources may lead to unworkable compromises.

\section{Material \& Methods}

In this part we will present and analyze Boulaq el-Dakrour participatory urban development project' three phases from 1999 till 2007, focusing on the different dimensions of the participatory program, in order to identify and demonstrate mechanisms and solutions for the manifold and interrelated problems which could then be applied in other informal areas.

\subsection{Case study analysis (Boulaq El Dakrour)}

\subsubsection{Introduction; location and basic information}

Boulaq el-Dakrour is located west of Central Cairo within the boundaries of Giza Governorate, which is divided into two administrative areas, one urban (51\% of the surface of the Governorate) and the other rural ( $49 \%$ of the surface). Boulaq el-Dakrour is one of Giza's eight urban districts and hosts about $17 \%$ of its nearly 5 million inhabitants (estimation of CAPMAS, 2001): it's internally subdivided in seven administrative sub-units. Boulaq el-Dakrour belongs to the typology of informal areas built on former cultivated fields: the ownership of the land is private, and although the conversion of the farms into residential plots took place without any official authorization from public authorities, the level of security of tenure is high.

The national statistical agency, CAPMAS, estimated the population of Boulaq El Dakrour at 530,089 in 2003 with an average annual population increase $1996-2003$ of $2.25 \%$, i.e. considerably higher than the Greater Cairo average of $1.9 \%$. A recent survey found that the average household size in 2003 was 4.86 , with $65.5 \%$ of households having five or less members. The population is comparatively young with $55 \%$ of all residents being younger than 25 years. $80 \%$ of households were reported to originate from Boulaq El Dakrour or elsewhere in Greater Cairo, over $18 \%$ of households have moved into the district within the past five years, $24 \%$ have lived in Boulaq El Dakrour for 6-20 years and 58\% for more than 20 years. (GTZ social survey 2003) The figures indicate that Boulaq El Dakrour continues to be an attractive location for newlyweds who look for affordable housing. Densification is reflected in the increasing number of renters. $58.5 \%$ of the residents are reported to be tenants and $4.6 \%$ are living in single rooms (KfW, 2003).

The socio-economic spectrum of inhabitants in Boulaq El Dakrour is relatively diverse and encompasses a considerable number of middle class inhabitants. However, there are also many poor and ultra- poor families who often live door to door with their non-poor fellow residents. A recent poverty survey found that $32.3 \%$ of all households fall below the lower and $50.8 \%$ below the upper poverty line. Poverty is particularly widespread among female-headed households, households with high dependency ratios and those with household heads who are illiterate, unemployed, underemployed or low-skilled workers. Adult literacy is $76.3 \%$ but school drop-out rates are alarming. (CAPMAS, 1998)

Only $46.4 \%$ of school age children are currently enrolled in schools compared to a national average of $86.0 \%$. (GTZ, 2003) Altogether $22.4 \%$ of household heads depend on casual labor, temporary jobs or seasonal employment. $19.7 \%$ of all main breadwinners are employees, $16.8 \%$ workers, $13.6 \%$ self-employed, $7.2 \%$ are drivers, $17 \%$ work in precarious jobs such as street vendors, domestic servants or home production and the rest are pensioners or unemployed. (Al Laithy, H. and Osman, M.O., 1996) Unemployment was reported at $6.3 \%$ of the labor force in 2002 i.e. lower than the national average of 9.0\%. (Institute of National Planning, 2007) It is particularly high among youth and new entrants into the labor market. (Ministry of Planning, 2007) Child labor is alarmingly widespread. $22.2 \%$ of children from $6-10$ years and $26.2 \%$ between $11-14$ years have been reported as working, most of them besides school. (El Shorbagi, M., 2003) (figure 3)

There is a serious lack of public and social services. There are no operational fire-fighting facilities, most health centers operate out of rented apartments under constant pressure to move, one vocational training center caters only to the needs of male school drop-outs and the only cultural center is poorly equipped and managed. The eight sports facilities do not offer appropriate space for girls and need urgent upgrading. The most dramatic problem is, however, the serious lack of school places combined with high drop-out rates. Many schools operate with two shifts and classes are dramatically overcrowded. The development plan for Boulaq El Dakrour has 
calculated that 1835 classrooms are needed by 2017 if official targets for school enrolment are to be met. Reasons for the lack of facilities are not only lack of public investment but also the inability of the responsible government agencies to get access to privately owned empty land. In addition, poor equipment, maintenance and management of public facilities result in generally low quality service provision. (Assaad, R. and Rouchdy, M.,2003)

\subsubsection{Environmental and Social Situation}

According to Elena, an inadequate solid waste collection system further contributed to the persistence of unhygienic and unhealthy conditions in the neighborhood, especially for kids whose playing grounds were littered with garbage. The Giza Beautification and Cleaning Authority, who is in charge of the collection and disposal of solid waste in the district, was unable to cope with the garbage daily production of the district, where also residues of cement and waste building material from neighboring districts are illegally transported at night-time. The private garbage collectors with a long tradition and a fundamental role in Cairo and Giza governorates, in return of a monthly fee pass door-to-door to collect solid waste directly from households, but low income areas (such as Boulaq el-Dakrour) do not constitute for them a profitable market because of the unwillingness of the residents to pay further fees (since every household already pays 3 EGP a month for this service together with the electricity bill) and because of the low value of the refuses produced. As a consequence, more than $20 \%$ of the solid waste (approximately 39 tons) remained uncollected.

From the social point of view, the most striking features appeared to be the lack of social and community services and in particular the insufficient coverage of both primary and preparatory schools, whose attendance in Egypt is a legal obligation. According to the CAPMAS, in Boulaq el-Dakrour the enrolment for the year $2003-2004$ was estimated to be about $61 \%$ in primary schools and $55 \%$ in preparatory school, and this considering the fact that in 16 out of 19 public schools have double shifts, that on average in each class there are 59 pupils and that about $15 \%$ of the pupils attend private or public schools. Ironically, whereas public schools are overcrowded and overloaded, in private schools (whose tuition fees can in certain cases be up to ten times the fees for public schools) there are approximately 4.400 vacant places.

Health facilities appeared to be relatively good for national standards. However, Boulaq General Hospital, two private hospitals and three health centers, together with the Boulaq Child Health Centre were barely sufficient to cover the needs of the district's population from a quantitative point of view, but not easy to access by all the population (especially in the south-west) and not appropriate to support the future population growth and the consequent increasing needs. Compared to other informal areas, Boulaq el-Dakrour presented though some advantages. In most of them in fact residential densities are so high and the urban fabric so compact that no vacant land is available for the installation of basic services such as schools, medical centers and cultural/recreational facilities: in Boulaq el-Dakrour, this was not an issue, since there are significant Government owned areas that could be employed for this purpose (Piffero, Elena 2009).

3.2 The Participatory Urban Development Project Boulaq El Dakrour; the first and second phase of the project, 1999-2001 and 2001-2003

The Participatory Urban Development Project Boulaq El Dakrour is part of the GTZ Participatory Local Development Program. The Boulaq El Dakrour project has started in 1998 in the framework of bilateral cooperation between the Arab Republic of Egypt and the Federal Republic of Germany with Giza Governorate as the counterpart and the district of Boulaq El Dakrour as the executing agency. The ultimate objective of the project is the improvement of the living conditions of the local population. The project is also envisaged to contribute to the development of better policies for informal areas and to poverty alleviation strategies. (figure 4)

In the framework of GTZ-PUMP, the BeD project started initially as a traditional upgrading project, focusing on environmental improvements, on the extension and amelioration of social services and on local economic development initiatives. Since focusing from the beginning on the whole district would have been excessively ambitious and inappropriate for a still essentially explorative phase, a pilot area hosting about 150.000 inhabitants was chosen in Old Boulaq for the first implementation phase (Piffero, Elena 2009).

GTZ-PUMP in BeD did not include in this first stage any Financial Components: it was based exclusively on a Technical Component with a limited budget of 1.2 million of Deutsche Marks of local subsidies for the improvement of existing facilities. The project consequently focused mainly at organizational, procedural and "soft" development measures which did not require major investments. Further financial contributions were expected to be mobilized from Egyptian governmental sources as well as from line Ministers and from the Social Development Fund, but the access of these resources proved to be more difficult than initially assumed, since the Egyptian counterpart perceived GTZ-PUMP in Boulaq as a classical donor project in which the responsibility for the upgrading is delegated (both in terms of economical financing and of implementation) to the cooperation agency.

During the first four years, the project has focused on environmental improvements, local economic development and social services in a pilot area with roughly 140,000 inhabitants. In addition, the project has tried to develop long-term development strategies and mechanisms of getting access to badly needed land for 
services. On behalf of the German Ministry for International Cooperation, the German Agency for Technical Cooperation (GTZ) has provided technical assistance to the project which included financial contributions for small demonstrative projects. During its new phase, the German Bank for Reconstruction (KfW) will provide a grant of 5 Million Euro to finance some of the needed technical infrastructure, mainly water and wastewater. (El Shorbagi, M., 2003)

The project was originally conceptualized as a traditional upgrading project focusing on infrastructure, urban planning, public space and environmental improvements. Physical upgrading measures were, however, not secured by clear agreements concerning the provision of necessary resources. Finance was expected to be mobilized exclusively from various Egyptian sources such as the governorate, line ministries and the Social Fund for Development. With very modest donor resources for investments, the project had very limited possibilities to finance pilot upgrading measures to demonstrate innovative approaches and thus also little leverage to negotiate substantial contributions from Egyptian agencies. Consultations with the local community, on the other hand, revealed that the priorities of the population did also not correspond to initial assumptions of local administration and the consultants who designed the project as an upgrading project. It turned out that community members were much more concerned with economic development and income generation, provision and improvement of social and community services as well as environmental improvements, particularly garbage collection. As a consequence, the project was re-conceptualized in accordance with the priority areas identified by the population. (The World Bank, Ministry of Planning, 2007)

Drawing on international and Egyptian experience, the project tried to promote the concept of locally negotiated and agreed development measures and strategies in order to improve the living conditions. Interventions were designed to provide learning experiences in participatory planning, decision making, execution and maintenance. This was done in the following key areas of action:

\subsubsection{Local environment and solid waste management:}

Project measures aimed at promoting joint responsibility of government agencies, the community and the private sector for garbage collection and the improvement of the environment. This included the training of environmental pioneers who were involved in public cleaning and awareness campaigns, environmental competitions and attempts to establish problem-solving mechanisms among the different actors. Since access to most residential streets is impossible for motorized garbage collection vehicles, the project established a container collection system in one pilot zone together with the Giza Beautification and Cleanliness Authority.

\subsubsection{Local economic development and employment}

The project has worked in close cooperation with an Egyptian NGO, El Mubadara, which is not only experienced in the areas of micro finance and business development services but tries also to experiment with new approaches that are tailored to the specific conditions in informal areas. Access to finance was identified as one of the key needs of local enterprises. The micro finance facility is oriented towards outreach and sustainability. (Nassar, H., 2003)

\subsubsection{Urban planning and improvement of public space}

Two pilot projects have been implemented to improve public space with the participation of the population, the district and the private sector that provided material and equipment at reduced prices. The first project included interventions such as street paving, creation of recreational space, tree planting and painting of house facades in El Amer Street and the adjacent lanes with a high number of users due to the location of several schools, a vocational training center and a youth club. The population participated actively in design, implementation, finance and the development of maintenance schemes. The second project was implemented in two of the main streets in Boulaq El Dakrour, Zenein Street and Nahyia Street, and consisted of integrated measures to solve problems related to traffic and congestion and a market of street vendors that caused considerable pollution. Changes in the street were designed to re-direct motorized vehicles and to separate pedestrian and other users to minimize accidents and secure smoother traffic flows.

\subsubsection{Social and community development}

Social and community development measures were designed to increase community mobilization and to promote organizational processes among active community members. This was crucial because the existing local NGOs proved to have only very little ambitions to expand their limited traditional and welfare-oriented activities. Women were one of the main target groups since they are one of the most deprived and at the same time motivated social groups in Boulaq El Dakrour. The project supported the establishment of a textile production unit to prove that textile production can be organized as a professional enterprise with marketable products rather than as the traditional sewing club where women only produce low quality garments for themselves and where activities tend to stop as soon as a machine breaks down. (Moritz, A., 2003)

\subsection{The Participatory Urban Development Project Boulaq El Dakrour; the third phase, 2004-2007}

After the first two mainly explorative phases, in 2004 the project underwent a series of strategic readdressing. A stronger coordination with MN project started, in the frame of the newly-named Participatory Development 
Program (PDP), which included also the Local Initiative component, the Policy Advisory Unit and Geographic Information System (GIS) unit. After the first pilot experience in Old Boulaq, the project area was extended to the whole district of $\mathrm{BeD}$, with an official target population of nearly 500.000 inhabitants (even though, as reported earlier, GTZ estimations talk about 1.000 .000 people).

Whereas in the previous phase the project in BeD was based essentially on a Technical Component, after a KFW Concept Study presented in 2004 the German and Egyptian Government agreed on the addition of a Financial Component with a value of up to 5 million $€$, targeted mostly at infrastructural improvement measures (especially in the fields of water and sewage, but also for environmental ameliorations and traffic management), whereas 0.5 million $€$ would be allocated for small community social projects not related to infrastructure. This decision stemmed from the acknowledgement of the opportunity of backing up the technical/advisory dimension of the project with a more substantial economical contribution, as emerged from the difficulties encountered in the initial stages of the project and related to the scarce leverage of the project on the counterpart. Furthermore, this decision was motivated also by the fact that, as underlined in the 2004 KFW report, other than GTZ projects no other activities involving foreign donors impacted directly upon $\mathrm{BeD}$ project area.

According to Piffero, Elena, during the project planning of the first two phases, the concept of "participative urban management" was left without a clear definition, and attempts to identify a more precise orientation regarding the procedural and organizational issues (and about what "participative urban management" could or should be) were avoided. It is possible to infer that a sort of silent consensus existed among the project staff (in $\mathrm{BeD}$ ) and its partners according to which participation is approximately referring to the involvement of the important stakeholders (including the residents) in the general planning and development process. This silent consensus might be an acceptable working agreement during the explorative phase, but after six years of pilot implementation the project team felt the need of better characterize the participatory approach and to clearly define a path to follow in order to translate it into practice. The 2004 phase started therefore with this reflection, first of all about the meaning of "urban management practices", which were defined as being "processes of consultation and planning". Such consultations require an incessant process of negotiation between the community and the government - represented by the local administration (Piffero, Elena 2009).

\subsubsection{Infrastructural projects}

Infrastructural projects have been and are at the moment still being implemented in the District under the responsibility of, but the major activity field of GTZ Team has focused on the effort to involve the stakeholders in the consultation process, both from the private sector which is composed by NGOs, natural leaders, representatives of women and youth, as well as small businessmen, and from the public one (Governorate, Local Popular and Executive Council, Swiss Fund for Development, public banks). In order to better concretize the promotion of a participatory approach, the team's reflection focused as well on the analysis of the Egyptian legal and administrative context and of previous development experiences in the country. The Egyptian laws already provide avenues for bottom-up participation but between the theory of the law and the actual practice there is often a gap: participation is intended as an invitation to the citizens to express their interests and to comment, but without letting them take part in the plan-making nor in its implementation, which is considered as a prerogative of the executive authorities. Even the fact that laws themselves are applied discretionally is more a structural issue than a problem of lack of capacity and professionalism of public employees and senior members of the public administration; as a consequence, PDP staff individuated the main challenge for the next phase in the effort of envisaging some kind of organizational features and mechanisms which would allow the interests and the resources of the local community to emerge and be effectively taken into account during the process of decision making and implementation (El Azzazi M. 2001). (figure 5)

\section{Results}

Community participation in local economic development has been largely limited to consultations. These consultations were, however, crucial to develop demand-driven service products. Sometimes, they produced unexpected results which stimulated new ideas. For many residents, however, buying clothes is an exciting event when the whole family makes a shopping excursion to the city center. Unexpected demand was instead identified in the area of computer repair and maintenance which is largely unavailable in the area and could become a niche market for a whole series of enterprises.

Community participation is most important in the areas of service provision and public space development. Simple measures of public space improvement which can be implemented quickly are more likely to succeed than complex interventions with individual components depending on each other for their success. This is particularly true during the initial stages of a project when basic concepts are still not widely understood. The success of the support for the privatization of solid waste management is too early to assess. The system is not yet functioning and has to overcome a number of legal and procedural obstacles. Community involvement will be crucial in awareness-raising, monitoring and problem-solving.

Local NGOs can play an important role as intermediates. In other areas of service delivery, community contributions are mainly provided as efforts, financial contributions can in most cases only be symbolic. Efforts 
represent, however, valuable resources which do not only increase cost efficiency but also effectiveness in service provision. Due to lack of public or private funds and donors' concerns with sustainability, there are however only limited possibilities to fund incentives and salaries for community members who want to become engaged in high quality service provision. As a consequence, many investments in training and capacity-building are lost if community members disengage from activities due to the necessity to earn income.

Investments in community development can be an important contribution to the development of civil society and the long-term re-orientation of development efforts towards citizens' rights based approach which includes also duties and responsibilities. Such an approach seems to be more appropriate than the romantic construction of the idea of the community. The inhabitants of large informal areas like Boulaq El Dakrour are extremely heterogeneous in terms of socio-economic background, education and life styles and have a wide range of different and often conflicting priorities and interests.

A promising area for cooperation on the local and the policy level is the area of strategic planning and budgeting. Although participatory planning, land management and service provision is seriously obstructed by lack of skills and the difficulty to access empty land, participatory budgeting can be developed into an instrument to promote a more rational use of resources. The first such exercise has contributed to increase the awareness of different departments in local administration that investments and interventions have to be planned as part of a strategic development plan which is based on an integrated concept and has to be implemented in a series of steps in accordance with negotiated priorities.

Consequent training and backstopping can help to build up the necessary capacities and can also promote the cooperation of different government agencies and other stakeholders. In order to achieve real impact, however, support is needed at the policy level. As long as funds cannot be used beyond the deadline of a financial year and are not earmarked for an area under a separate project number, it is not possible to actually access the funds and implement the measures as planned. In view of the existing political and administrative practice as well as the lack of technical understanding and true representative bodies, community participation will probably remain limited to consultations and will not include direct participation in decision-making.

\section{Discussion}

Experience shows that technical assistance projects have little chance to be accepted and adopted without a substantial component that allows for the demonstration of innovative solutions to development problems on a larger scale or at least provides the project with sufficient leverage to mobilize active support of government actors. In view of the highly personalized management structures at the senior levels of local administration, project measures depended often on the personal support of the district chief. Since district chiefs are appointed and not elected, they are not really accountable to the population and can be changed at any time which actually happened five times during the first six years of the project. Continuity in planning and implementation is thus difficult to achieve. The longest serving district chief was also particularly reluctant to engage in innovative approaches which always imply some risks that could challenge his personal career. (GTZ, 2007)

A more pro-active role of local administration does also need pressure from below, i.e. from local communities that are capable to start independent initiatives and lobby for support. However, the only representative bodies of the population, the Local Popular Councils, tend to be more concerned with party politics and personal ambitions than with their constitutional role to advocate the interests and development needs of the population. Having often been described as a classical semi-rental state, the legitimacy of national as well as local government is mainly derived from its ability to distribute resources a large portion of which comes from rental revenues. Transparency and accountability is thus extremely low and clientele networks prevail over formal structures of democratic representation.

Community participation in densely populated areas with little social consistency, a low level of popular organization and a high degree of secrecy is a particular challenge. As highlighted above, clientele networks are an important channel to distribute resources and facilitate official procedures. This has created a recipient mentality among the residents and contradicts the concept of collectively negotiated solutions and joint responsibility. Although it has long become obvious that the State is no longer able to provide for urgent development needs, a vision of how popular participation can add to a more efficient and effective use of available resources is almost completely missing so far. In addition, the creation of a sense of common interest and joint responsibility is not an easy task if the area is perceived as a hotbed for criminals, terrorists and all sorts of socially unacceptable behavior. These perceptions are partially internalized by local residents and have created an atmosphere of anonymity, indifference and distrust. Project measures must therefore aim at creating sufficient momentum to facilitate the development of a joint vision.

Direct action and the promotion of participatory mechanisms have to go hand in hand. Awareness-raising campaigns, for example, which are designed to mobilize active community participation for interventions to improve the environment, can only have an impact if embedded in other activities which are implemented in parallel and demonstrate the seriousness and feasibility of the proposed solutions. Attempts to involve community members in participatory planning exercises can only be successful if they are accompanied by quick, 
visible measures that correspond to felt needs and priorities and demonstrate the positive effects of cooperation. The upgrading of El Amer Street can be regarded as a success in this respect. Although the project was not replicated on a wider scale and sustainable mechanisms for maintenance could not be established to the same extent as initially envisaged, the highly visible action in public space increased trust, credibility and active participation. It stimulated other initiatives such as the establishment of the IT center in the nearby youth club as well as activities in local schools.

Finally, for an urban development process to be really participative, it cannot focus only on the upgrading of informal, underserved districts, but it should include the broader context of land and housing issues. The Egyptian government should be led to the adoption of pro active, preventive interventions to limit and redirect the unregulated growth of urban areas, rather than trying to catch up to informal development with post hoc upgrading programs which represent, on the long run, only partial, palliative measures. This ambitious goal, nevertheless, is not included in the project targets (Piffero, Elena 2009).

\section{Conclusion}

Participation is now widely recognized as a basic operational principle of development, but the debates around this approach are fervent. Conventionally, the participatory approach is considered as the reaction to the shortcomings of top down development practices, externally imposed and expert oriented (Chambers R. 1983). The advantage of these new approaches is that they are centered on the role of the local community as a primary actor that should be allowed (and enabled) to influence and share the responsibility (and possibly the costs) of the development process affecting their lives. As U. Kothari underlines, "participatory approaches to development, then, are justified in terms of sustainability, relevance and empowerment" (Kothari U. et al, 2001). While accepted development literature, as well as development mainstream agencies as the World Bank and UNDP, have tended to promote the pervasive belief that participation is intrinsically good, more recently this enthusiasm has been put back into perspective by a series of critical interventions in specialized reviews, and by some interesting publications. The main point advanced by these critiques is that participatory development interventions do not always trigger these mechanisms of liberation and distribution of power that the theory suggests, and that in certain cases they might actually contribute to the perpetration of exclusionary practices.

The case study shows that technical assistance projects must be accepted by a slim chance and was adopted without a key allows the demonstration of innovative solutions to the problems of large-scale development or at least provide the project with sufficient leverage to mobilize the active support of government agencies. A more active role in local government should not necessarily the pressure from below, one of the communities that are able to launch independent initiatives and lobby for support. Community participation in areas of high population density and low social cohesion and a low level of popular organization and a high degree of confidentiality is a particular challenge. To work and to strengthen mechanisms of participation must go together. On the other hand, we could conclude that, community participation in local economic development has been largely limited to consultations, and is most important in the areas of service provision and public space development. With regard to the important role of Local NGOs that can play, the investments in community development can be an important contribution to the development of civil society and the long-term re-orientation of development efforts towards a citizens' rights based approach which includes also duties and responsibilities.

What emerges from case study analysis is that participatory development processes have no predetermined outcomes: they can lead to transformation and change in the political and social patterns, but sometimes they do not really affect the way decisions are taken and implemented and the relations of power among the various stakeholders. In this sense, it is possible to differentiate between two types of participation: participation as social inclusion and participation as socio political transformation. Participation as social inclusion refers to a dynamic in which those groups and individuals that were previously marginalized are involved in the development process, but in ways that might reinforce the very same exclusionary mechanisms which caused their marginalization in the first place (Kothari U. 2001). Participation as transformation, on the contrary, refers to a process which modifies and changes the relations of power that objectify and subjugate people, leaving them without a voice (Cornwall A. 2000). In certain cases, even micro level project somehow succeed in triggering broader political and social transformation that allow the marginalized population to become integrant part of the social and political systems, and enable it to get full citizenship rights (including first stage responsibility in the decision making and a full reintegration in the allocation of governmental resources (Piffero, Elena 2009).

\section{Acknowledgements}

The author appreciate the help of the GTZ office in Cairo and Participatory Development Program in Urban Areas to support this research; hence he would like to thank the responsible of this Agency for their cooperation and supplying data used in this study. And acknowledge Elena Piffero for the helpful studies and analysis that support this paper. The author would like to acknowledge the reviewers for their helpful and constructive comments that help in improving this paper. 


\section{References}

ADB. (2006). Report and Recommendation of the President to the Board of Directors on a Proposed Loan to Mongolia: Urban Development Sector Project, Supplementary Appendix L (Community Participation Strategy). Manila.

Al Laithy, H. and Osman, M.O. (1996). Profile and Trend of Poverty and Economic Growth, Institute of National Planning, Cairo 1996.

Assaad, R. and Rouchdy, M. (2003). Poverty and Poverty Alleviation Strategies in Egypt, Cairo Papers in Social Science, Vol. 22 (1), Cairo 2003.

CAPMS, Central Agency for Public Mobilization and Statistics, 1996 population census, Cairo 1998

Chambers R. (1983). Rural Development: Putting the Last First, Longman, London; CHAMBERS R. (1997), Whose Reality Counts? Putting the First Last, IT Publications, London.

Cornwall A. (2000). Making a difference? Gender and participatory development, IDS Discussion Paper 138. IDS, University of Sussex, p. 28.

Datt, G. et. al. (1997). A Profile of Poverty in Egypt: 1997, International Food Policy Research Institute, Cairo 1997.

El Azzazi M. (2001). Local Organisations Involved in Upgrading Informal Settlements: Laws and Regulations, Policy Discussion Paper prepared for the Participatory Urban Management Program, Arab Republic of Egypt (Ministry of Planning) and GTZ.

El Shorbagi, M. (2003). Demographic and Socio-Economic Analysis of Boulaq El Dakrour, Giza 2003.

El Shorbagi, M. (2003). Poverty Assessment Boulaq El Dakrour - Household Sample Survey, study on behalf of KfW, Cairo 2003.

GTZ. (2003). Participatory Urban Development Project Boulaq El Dakrour, Boulaq El Dakrour Guide Plan 2004 - 2017, Vol. 1 and 2, Giza 2003.

GTZ, Participatory Urban Development Project Boulaq El Dakrour, social survey - Study on Buildings and Residents in Boulaq El Dakrour (study conducted in cooperation with Cairo University/Faculty for Urban Planning in preparation for strategic development plan), Cairo August 2003.

GTZ. (2007). Participatory Urban Development Project Boulaq El Dakrour, Urban Upgrading Needs Assessment, Giza 2007.

Institute of National Planning, Egypt Human Development Reports (1996, - 2007)

Korten, David, C. (1987). Micro policy reform: the role of private voluntary development agencies. Lincoln Institute of land policy, 1987.

Kothari U. (2001). Power, Knowledge and Social Control in Participatory Development, in KOTHARI U. et al, p. $143 \neg 145$.

Kothari U. et al. (2001). The case for Participation in Development, in KOTHARI et al, p. 5.

Kreditanstalt für Wiederaufbau. [Loan for Reconstruction] (KfW), Poverty survey - Concept Study for FC Intervention in Boulaq El Dakrour, Giza 2003.

Ministry of Planning. (2007). United Nations Development Program, Subjective Poverty and Social Capital Towards a Comprehensive Strategy to Reduce Poverty, Cairo, April 2007.

Moritz, A., Promotion of Private Sector and Employment in Boulaq El Dakrour, Giza 2003.

Moser, Caroline O.N. (1987). Approaches to community participation in urban development programs in third world countries, In Bamberger, ed. Readings in Community Participation, Washington, D.C :EDI, The World Bank, 1987.

Moser, Caroline O.N. (1987). Approaches to community participation in urban development programs in third world countries, In Bamberger, ed. Readings in Community Participation, Washington, D.C :EDI, The World Bank, 1987.

Nassar, H. (2003). Survey on Socio Economic Conditions of Work in Greater Cairo, Preliminary Report, Social Research Center, American University in Cairo, Cairo 2003.

Piffero, Elena. (2009). Struggling for Participation, Experience of a 10-year Development Program, Boulaq el-Dakrour, GTZ,

Egypt. http://egypt-urban.pdp-gtz.de1.cc/wp-content/uploads/2009/12/Elena-Piffero-Paper_resized.pdf.

Schubeler, Peter. (1996). Participation and Partnership in urban infrastructure management, UMP, The world Bank, Washington, D.C. 1996.

Smith, M. K. (1999, 2006). 'Community participation', the encyclopaedia of informal education, www.infed.org/community/b-compar.htm. 
The World bank. (2007). Ministry of Planning/Government of Egypt, Poverty Reduction in Egypt: Diagnosis and Strategy, Cairo, June 2007.
Abbreviations:
BeD Boulaq El Dakrour
CAPMASCentral Agency for Public Mobilization And Statistics
GIS Geographic Information System
GTZ German Technical Cooperation
KfW German Bank for Reconstruction
NGO Non Governmental Organization
PDP Participatory Development Program
PUMP Participatory Urban Management Program
UNDP United Nations Development Program

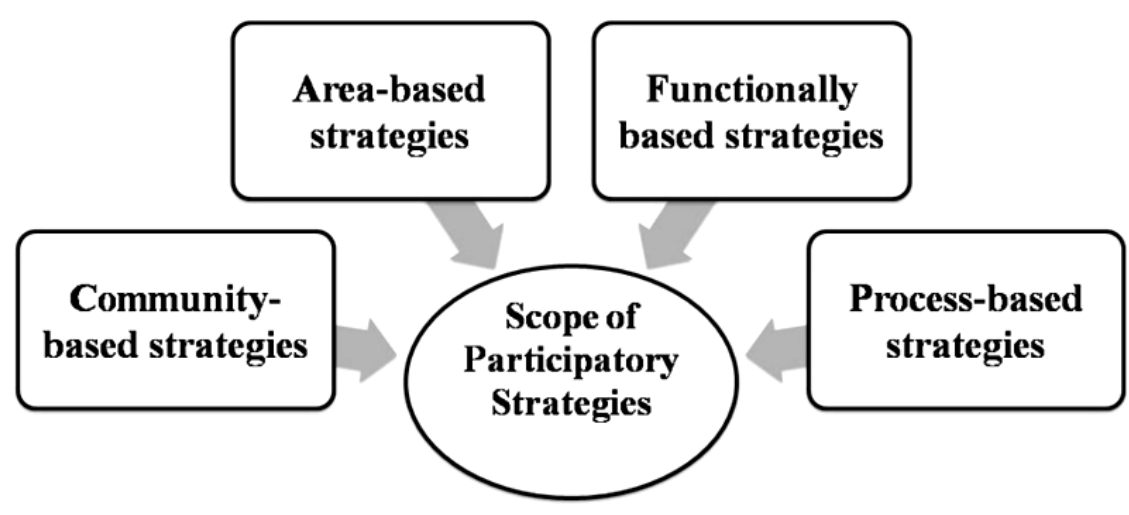

Figure 1. illustrates the different strategies of participation in urban development projects

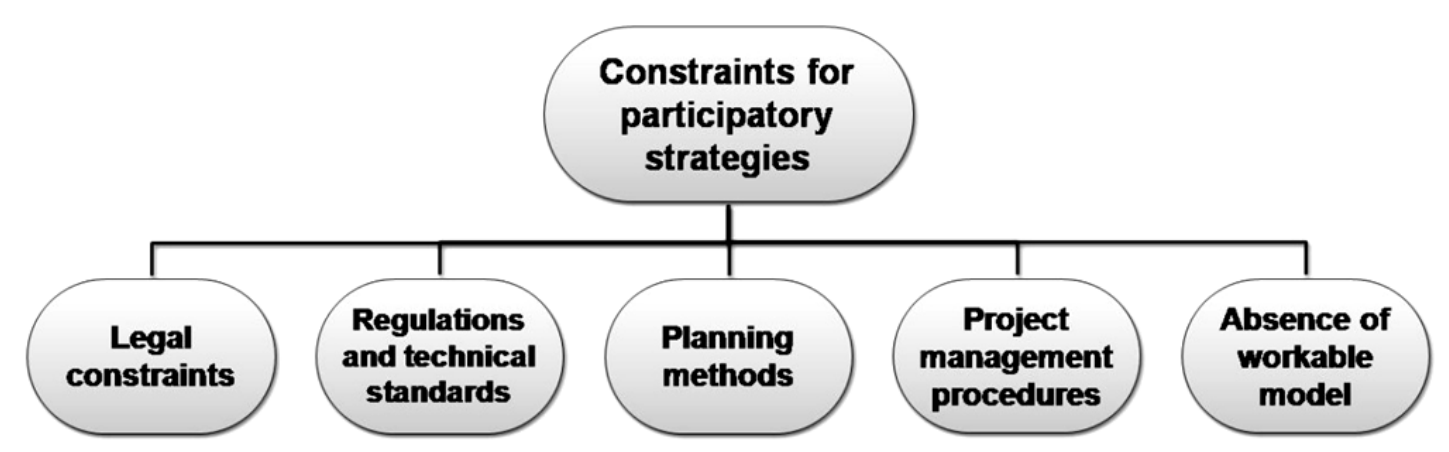

Figure 2. illustrates the different constraints for participatory strategies in urban development projects 


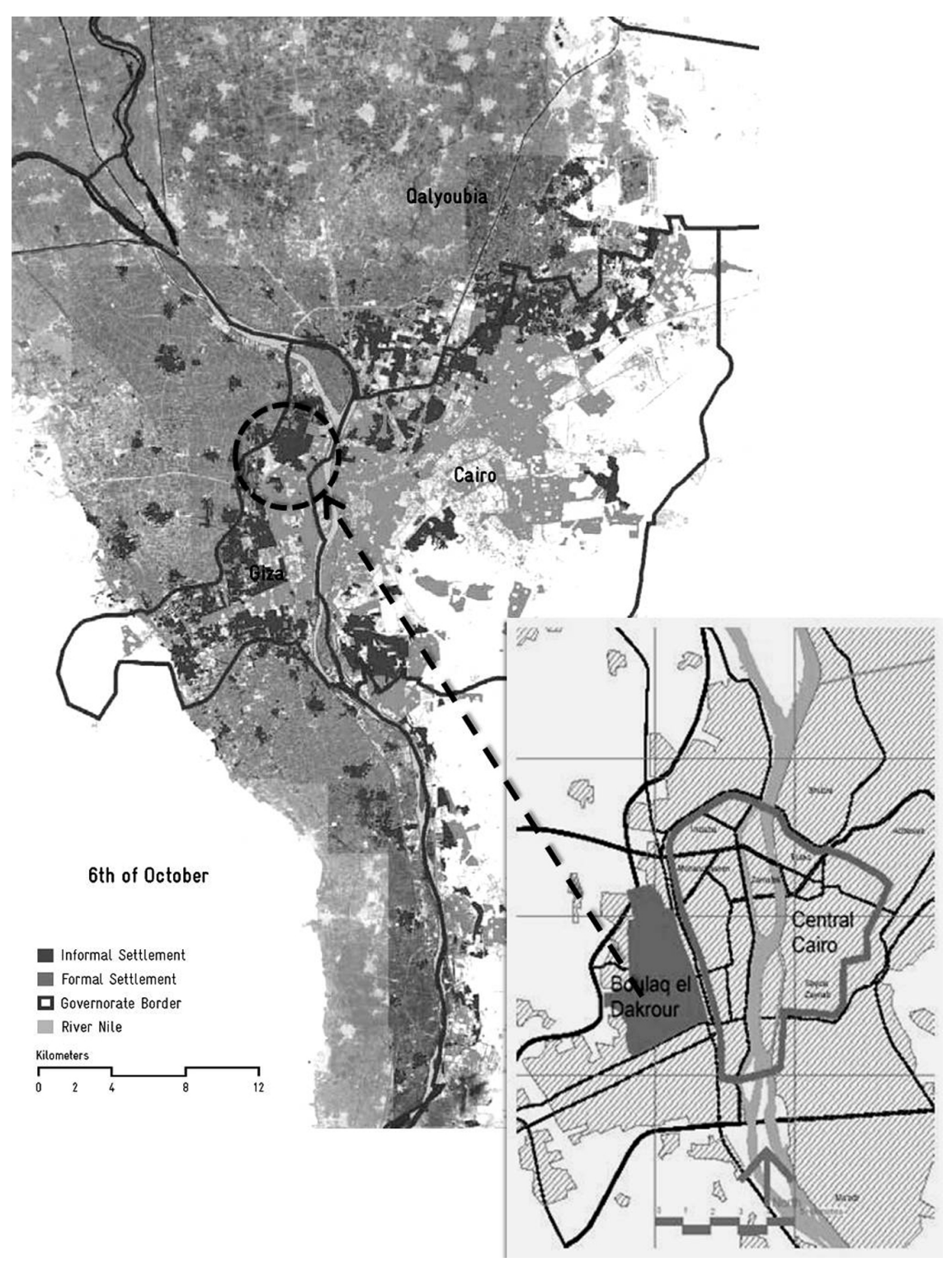

Figure 3. illustrates the distribution of Income Among Households, Poverty Status by Employment Situation of Household Head, and Poverty Status of Individuals ( $>17)$ by Educational Level of Boulaq el Dakrour on Cairo map.

Source; KFW poverty survey 200 \& Egypt Human Development Report 2003, NIP/UNDP3
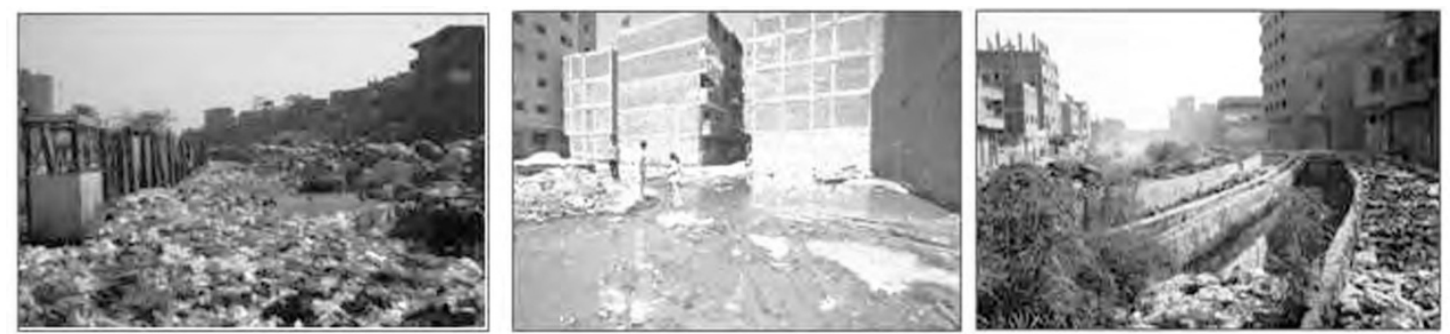

Figure 4. Illustrates sewage and sold waste problems at the beginning of the $\mathrm{BeD}$ project.. CGTZ.

Source; Piffero, Elena 2009. 


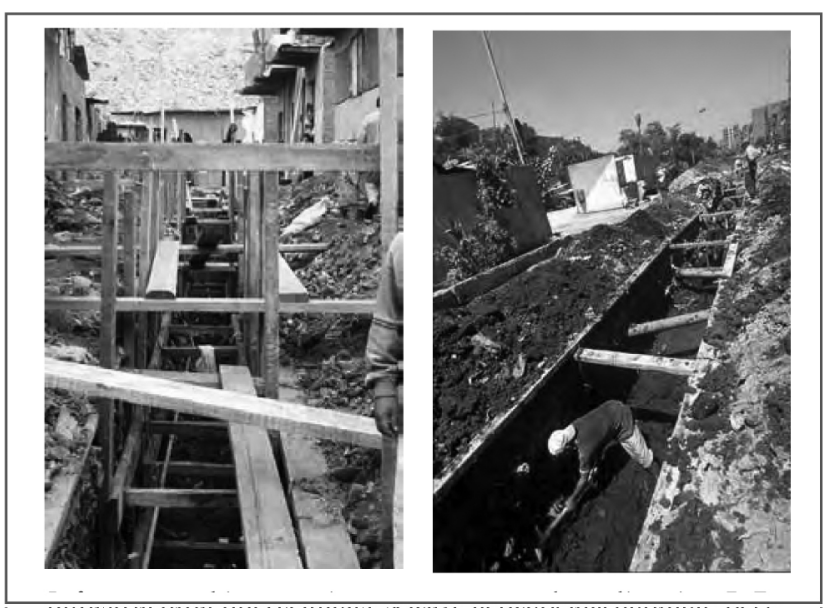

Figure 5. illustrates Infrastructural interventions: sewage network amelioration, BeD. CGTZ. Source; GTZ, 2007, Piffero, Elena 2009 